\title{
Developmental Aspects of Cystine Transport in the Dog
}

\author{
JOHN W. FOREMAN, MARVIN S. MEDOW, KENNETH C. BOVEE, AND STANTON SEGAL \\ Department of Pediatrics and Medicine, University of Pennsylvania, School of Medicine, University of \\ Pennsylvania School of Medicine, and Division of Biochemical Development and Molecular Diseases, The \\ Children's Hospital of Philadelphia, Philadelphia, Pennsylvania; Departments of Pediatrics and Physiology, New \\ York Medical College, Valhalla, NY 10595 [M. S. M.]; ** Department of Clinical Studies, School of Veterinary \\ Medicine, University of Pennsylvania, Philadelphia, Pennsylvania 19104 [K. C. B.]
}

\begin{abstract}
Developmental changes in cystine transport by the canine kidney were examined both in vivo and in vitro. Renal clearance studies indicated that cystine was one of the more incompletely reabsorbed amino acids at birth, but its reabsorption approaches adult levels by 21 days. Concomitantly, cystine uptake by isolated renal cortical tubule fragments from immature dogs was slower than that by renal tubules from adult dogs. Both age groups rapidly metabolized the transported cystine. This metabolism was principally to cysteine, but also small amounts of reduced glutathione were formed from the transported cystine. Concentration dependence studies indicated two transport systems for cystine uptake in both the immature and the adult dog. Both transport systems in the 1-wk-old dog had a somewhat greater affinity for cystine than the corresponding system in the adult, but this was offset by the markedly lower maximal transport rates for these systems in the 1-wk-old dog. The high affinity system was inhibited by lysine in tubules from both age groups. In the dog, the rise in the tubular reabsorption of cystine with maturation could, in part, be explained by an increase in the number of transport sites for cystine. (Pediatr Res 20: 593-597, 1986)
\end{abstract}

\section{Abbreviation}

DR, distribution ratio

Cystinuria is one of the most common inherited transport disorders in man (1). Individuals afflicted with this disease have recurrent cystine stone formation and often renal damage if untreated. Because of its clinical importance as well as its biological significance much research has been directed at understanding cystine transport by the kidney.

A disease occurs in many breeds of dogs which in many respects resembles human cystinuria (2-5). In previous reports from this laboratory the examination of cystinuric dogs has shown that there is defective renal tubular reabsorption of cystine $(2,3,5)$. The large hyperexcretion of lysine almost invariably seen in the human disorder is not regularly observed in the canine entity. Deranged renal handling of lysine, however, can be uncovered with lysine loading (2).

Another situation in which increased excretion of cystine

Received December 13, 1985; accepted February 13, 1986.

Correspondence John W. Foreman, M.D. Children's Hospital of Philadelphia, 34th Street \& Civic Center Boulevard, Philadelphia, PA 19104.

This work has been supported by Grant AM 10894 from the National Institutes of Health, Bethesda, MD and Grant 841122 from the American Heart Association. occurs is during the newborn period. This "physiological" cystinuria of the normal newborn has been noted in a number of animal species, including man (18). There is evidence that suggests that there is increased cystine excretion in the newborn dog (6). Therefore, studying cystine transport in the immature dog where reabsorption is incomplete may offer insights into mechanisms responsible for the inherited abnormality and give information concerning the nature of changes in renal amino acid transport with maturation. Because of this we have examined cystine handling by the kidney of the developing dog in vivo and by isolated renal cortical tubular fragments in vitro.

\section{MATERIALS AND METHODS}

The renal clearance of amino acids was measured in 17 mongrel dogs of either sex at various ages: 5 days, 21 days, 8 wks, 12 wks, and greater than a year using methods previously described $(2,7,8)$. The amino acid clearance and glomerular filtration rate were measured simultaneously, the latter by the renal clearance of inulin and endogenous creatinine. The 8- and 12-wk pups were maintained on a standard commercial diet and fasted for $12 \mathrm{~h}$ prior to the studies. The younger pups were withheld from nursing for $6 \mathrm{~h}$ prior to study. Inulin was determined by a modification of the method of Davidson and Sackner (9). Creatinine was determined by the Jaffe reaction (10). Individual plasma and urinary amino acids were determined by a modification of the method of Stein and Moore (11) using a Beckman Model 119 C Amino Acid Analyzer employing a lithium citrate buffer system.

Mongrel dogs of either sex from two different age groups, 5 to 7 days old, and more than 1 yr old, were used for the in vitro studies. Isolated renal cortical tubule fragments were prepared by a modification (8) of the method of Burg and Orloff (12). Uptake studies of $\left[{ }^{35} \mathrm{~S}\right]$-L-cystine using isolated tubules suspended in Krebs-Ringer bicarbonate buffer containing $10 \mathrm{mM} \mathrm{Na}{ }^{+}$ acetate and $5 \%(\mathrm{vol} / \mathrm{vol})$ fetal calf serum were performed in Burg-Orloff flasks with continuous bubbling of a $95 \% \mathrm{O}_{2}-5 \%$ $\mathrm{CO}_{2}$ mixture (13).

$\mathrm{DR}$ of radioactivity, $\mathrm{cpm} / \mathrm{ml}$ of intracellular fluid to $\mathrm{cpm} / \mathrm{ml}$ of incubation medium, were calculated as described (14). The intracellular fluid volume was calculated as the difference between the total tissue fluid, the wet weight minus the weight after overnight dessication, and the volume of the trapped fluid. The trapped fluid space in the isolated tubules was determined with $\left[{ }^{14} \mathrm{C}\right]$-poly(ethylene glycol) as previously described (8).

Metabolism of the transported label was determined by performing thin-layer chromatography of $\mathrm{N}$-ethylmaleimide treated extracts of the intracellular fluid of tubules after incubation with $\left[{ }^{35} \mathrm{~S}\right]$-cystine as previously described $(13,14)$

In concentration dependence studies, tubules were incubated 
with $\left.0.1 \mu \mathrm{Ci} / \mathrm{ml}{ }^{35} \mathrm{~S}\right]$ cystine plus unlabeled cystine to give the desired final concentration over the range of 0.01 to $0.7 \mathrm{mM}$. The observed transport kinetic parameters were determined from a Hofstee plot of the transport data. The best fit of these data was obtained by the least squares method using a programmable calculator. In parallel experiments, $3 \mathrm{mM}$ lysine was added to determine its affect on cystine uptake. All analyses of data for statistical significance were made using Student's $t$ test.

$\left[{ }^{14} \mathrm{C}\right]$-poly(ethylene glycol $)(21.7 \mathrm{mCi} / \mathrm{g})$ and $\left[{ }^{35} \mathrm{~S}\right]-\mathrm{L}-$ cystine ( $760 \mathrm{mCi} / \mathrm{mmol}$ ) were obtained from Amersham Corp., Arlington, IL. Purity of the labeled cystine was $95 \%$ or better as determined by thin-layer chromatography (15) and ion exchange chromatography with an amino acid analyzer (11). Additional chemicals were obtained from commercial sources and were of the highest purity available.

\section{RESULTS}

Renal clearance studies. The fractional reabsorption of cystine and dibasic amino acids by canine pups is shown in Table 1 . In 5 -day-old dogs the fractional reabsorption of cystine was $67 \%$ of the filtered load; yet the reabsorption of the dibasic amino acids was nearly that of the older animals except for a slightly lower ornithine reabsorption. The fractional cystine reabsorption was the same as the glycine reabsorption reported earlier for the newborn dog and is among the most incompletely reabsorbed amino acids measured at this age (8). By 21 days, cystine reabsorption was $99 \%$ of the filtered load, a value equal to adult reabsorption.

In Table 2, the changes in plasma concentrations of cystine and dibasic amino acids with maturation are shown. One-weekold puppies had a somewhat lower plasma cystine concentration compared to adult dogs and a somewhat higher lysine concentration, but these differences were not statistically significant $(p$ $<0.1)$. The largest change is a fall in plasma ornithine with maturation. The ratio of dibasic amino acids to cystine is slightly higher in the 1 wk old (7:1) compared to the adult (5:1), but this change is not significant. Thus, it appears that the lower fractional reabsorption of cystine in the $1 \mathrm{wk}$ old is related to impaired tubular reabsorption and not increased competition by dibasic amino acids. To examine this, cystine uptake was studied in isolated renal cortical tubules from 5 to 7-day-old puppies and adult dogs.

Cystine uptake by isolated tubules with time. Isolated renal tubules from 1-wk-old and adult dogs had a progressive rise in $0.025 \mathrm{mM}\left[{ }^{35} \mathrm{~S}\right]$-cystine uptake with time which had not reached a steady-state by $60 \mathrm{~min}$ of incubation (Fig. 1). The uptake by tubules from the adult was consistently greater than that of the newborn. This difference was statistically different at 5,15 , and

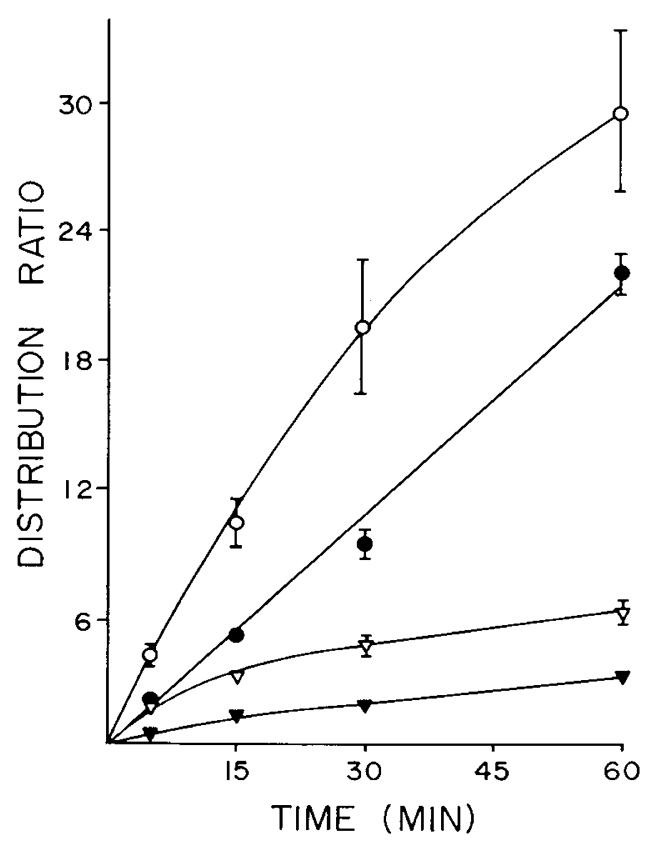

Fig. 1. Time-dependent uptake of 0.025 and $0.5 \mathrm{mM}\left[{ }^{35} \mathrm{~S}\right]-\mathrm{L}-\mathrm{cystine}$ by isolated dog renal cortical tubules from newborn and adult dogs. Uptake of $0.025 \mathrm{mM}$ cystine is represented by circles and uptake of 0.5 $\mathrm{mM}$ cystine by triangles. Closed figures represent uptake by newborn tubules and open figures represent uptake by adult tubules. Each point represents the mean \pm SEM of at least eight determinations. SEs not shown are within the size of the point.

Table 1. Fractional reabsorption of amino acids*

\begin{tabular}{lllccc}
\hline & \multicolumn{5}{c}{ Age of pups } \\
\cline { 2 - 6 } & $\begin{array}{c}5 \text { days } \\
(n=10)\end{array}$ & $\begin{array}{c}21 \text { days } \\
(n=3)\end{array}$ & $\begin{array}{c}8 \text { wk } \\
(n=2)\end{array}$ & $\begin{array}{c}12 \text { wk } \\
(n=2)\end{array}$ & $\begin{array}{c}\text { Adults } \\
(n=8)\end{array}$ \\
\hline Amino acid & $67 \pm 8$ & $99 \pm 0.3$ & 100 & 100 & $100 \pm 0$ \\
Cystine & $98 \pm 0.6$ & $99 \pm 0.1$ & 100 & 100 & $99 \pm 0$ \\
Lysine & $99 \pm 0.4$ & $99 \pm 0.1$ & 100 & 100 & $100 \pm 0$ \\
Arginine & $91 \pm 3$ & $100 \pm 0$ & 99 & 100 & $99 \pm 0$ \\
\hline
\end{tabular}

* The fractional reabsorption of several amino acids in dogs of various ages determined by standard renal clearance techniques, as described in the text. Values shown are the means \pm SEM of three determinations in each dog studied at 21 days, $8 \mathrm{wk}, 12 \mathrm{wk}$, and adulthood. Among the 5day-old pups, measurements were made in triplicate in four pups, and as individual measurements in the remaining six pups. $n=$ number of dogs.

Table 2. Changes in plasma amino acid concentrations ( $\mathrm{nmol} / \mathrm{ml}$ ) with age*

\begin{tabular}{cccccc}
\hline & \multicolumn{5}{c}{ Age of pups } \\
\cline { 2 - 6 } & $\begin{array}{c}5 \text { days } \\
(n=10)\end{array}$ & $\begin{array}{c}21 \text { days } \\
(n=3)\end{array}$ & $\begin{array}{c}8 \text { wk } \\
(n=2)\end{array}$ & $\begin{array}{c}12 \text { wk } \\
(n=2)\end{array}$ & $\begin{array}{c}\text { Adults } \\
(n=8)\end{array}$ \\
\hline Amino acid & $64 \pm 5$ & $101 \pm 24$ & 118 & 40 & $73 \pm 4$ \\
Cystine & $279 \pm 28$ & $328 \pm 88$ & 148 & 114 & $214 \pm 38$ \\
Aysine & $118 \pm 14$ & $180 \pm 39$ & 107 & 60 & $140 \pm 13$ \\
Ornithine & $48 \pm 7$ & $63 \pm 6$ & 34 & 23 & $16 \pm 5$ \\
\hline
\end{tabular}

* Plasma amino acid concentrations in dogs of varying ages determined by ion exchange chromatography as described in "Materials and Methods." Each value represents the mean \pm SEM. $n=$ number of dogs. 
Table 3. Intracellular metabolism of transported cystine*

\begin{tabular}{|c|c|c|c|c|c|}
\hline Age & $\begin{array}{c}\text { Concentration } \\
(\mathrm{mM})\end{array}$ & $\begin{array}{c}\text { Incubation time } \\
(n)\end{array}$ & Cysteine & GSH & Cystine \\
\hline \multirow[t]{3}{*}{ Newborn } & 0.025 & $\begin{array}{r}5 \min (7) \\
60 \min (8)\end{array}$ & $\begin{array}{l}97 \pm 2 \\
88 \pm 4\end{array}$ & $\begin{array}{l}1 \pm 0.4 \\
6 \pm 1\end{array}$ & $\begin{array}{l}2 \pm 2 \\
6 \pm 3\end{array}$ \\
\hline & 0.5 & $5 \min (4)$ & 100 & 0 & 0 \\
\hline & & $60 \min (3)$ & $75 \pm 4$ & $7 \pm 3$ & $18 \pm 1$ \\
\hline \multirow[t]{2}{*}{ Adult } & 0.025 & $5 \min (3)$ & $95 \pm 4$ & $5 \pm 4$ & 0 \\
\hline & & $30 \min (3)$ & $93 \pm 4$ & $5 \pm 2$ & $2 \pm 2$ \\
\hline
\end{tabular}

* Renal cortical tubules were isolated from adult and newborn kidney and incubated for various times with $0.5 \mu \mathrm{Ci} / \mathrm{ml}\left[{ }^{35} \mathrm{~S}\right]-\mathrm{L}-\mathrm{cystine}$ plus unlabelled cystine to obtain the desired concentration. After incubation, the tubules were lysed in the presence of $40 \mathrm{mM}$ N-ethylmaleimide to form stable adducts and thin-layer chromatography was performed on the lysate as previously described $(10,14)$. The values represent the percentage \pm SEM of the total intracellular radioactivity found in cystine or its metabolites. $(n)$ represents the number of determinations.

$30 \mathrm{~min}(p<0.01$ at 5 and $15 \mathrm{~min}$, and $p<0.05$ at $30 \mathrm{~min})$. The uptake of $0.5 \mathrm{mM}$ cystine by tubules from adult dogs was progressive and did not reach a steady-state by $60 \mathrm{~min}$ of incubation. The uptake of $0.5 \mathrm{mM}$ cystine by tubules from 1 -wk-old dogs was also progressive and did not reach a steady-state by 60 min. As was noted with $0.025 \mathrm{mM}$ cystine, the uptake of 0.5 $\mathrm{mM}$ cystine by tubules from adult dogs was higher than that of tubules from 1-wk-old dogs at each time point studied and this difference was statistically significant $(p<0.01)$.

Metabolism of labeled cystine. Because previous reports of cystine uptake by rat renal tubules showed extensive metabolism $(13,14)$, this was studied in isolated dog tubules. The results are shown in Table 3 . With both a high and low medium concentration of cystine, the predominant fate of the transported labeled cystine was a chemical reduction to cysteine with some incorporation into glutathione in the newborn tubules. Similarly, most of the intracellular label in adult dog tubules was found as cysteine. This marked chemical reduction of the transported labeled compound is a hallmark of cystine uptake in numerous tissues from several species, including renal cortical slices from the $\operatorname{dog}(5,7,13,14,16)$. Because of the extensive metabolism of transported label, a chemical gradient of cystine was not developed and the DR reflects only a radioactivity gradient.

Concentration dependence of uptake. The concentration dependence of cystine uptake was examined using tubules from adult and newborn dogs over the substrate concentration range of 0.01 to $0.7 \mathrm{mM}$. These studies were done using a time interval as close to initial rate as possible, but which would allow us to discern a variation in the uptake with a change in medium concentration (8). The time interval employed was $5 \mathrm{~min}$ of incubation with adult tubules and $15 \mathrm{~min}$ with newborn tubules. The uptake of cystine over the 15-min time interval was linear or nearly so, allowing comparison with the uptake over 5 min for the adult tubules. In tubules from the adult dogs, a twolimbed curve was observed on a Hofstee plot of the data, indicating multiple transport systems for cystine uptake (Fig. 2). The parameters describing cystine transport are shown in Table 4. The mean values of the apparent kinetic parameters of the two cystine transport systems were $\mathrm{Km}_{1}=0.16 \pm 0.02 \mathrm{mM}, \mathrm{Vmax}_{1}$ $=0.12 \pm 0.03 \mathrm{mmol} /$ liter intracellular fluid per min over the concentration range of $0.01-0.1 \mathrm{mM}$ and $\mathrm{Km}_{2}=0.62 \pm 0.08$ $\mathrm{mM}, V \max _{2} 0.31 \pm 0.03 \mathrm{mmol} /$ liter intracellular fluid per min over the concentration range of $0.1-0.7 \mathrm{mM}$.

A Hofstee plot of the concentration dependence of cystine uptake by newborn tubules also gave a two-limbed curve (Fig. 3 ). The apparent kinetic parameters for cystine uptake in these newborn animals are shown in Table 4. The means of the kinetic parameters of the five newborn dogs were $\mathrm{Km}_{1}=0.07 \pm 0.01$ $\mathrm{mM}, \mathrm{Vmax}_{1}=0.03 \pm 0.01 \mathrm{mmol} /$ liter intracellular fluid per min over the concentration range of $0.01-0.1 \mathrm{mM}$ and $\mathrm{Km}_{2}=$ $0.32 \pm 0.03 \mathrm{mM}, V_{\max _{2}}=0.08 \pm 0.02 \mathrm{mmol} /$ liter intracellular fluid per min over the concentration range of $0.1-0.7 \mathrm{mM}$.

The $\mathrm{Km}$ values for the newborn were significantly different from the corresponding adult values for both the high affinity $(p$

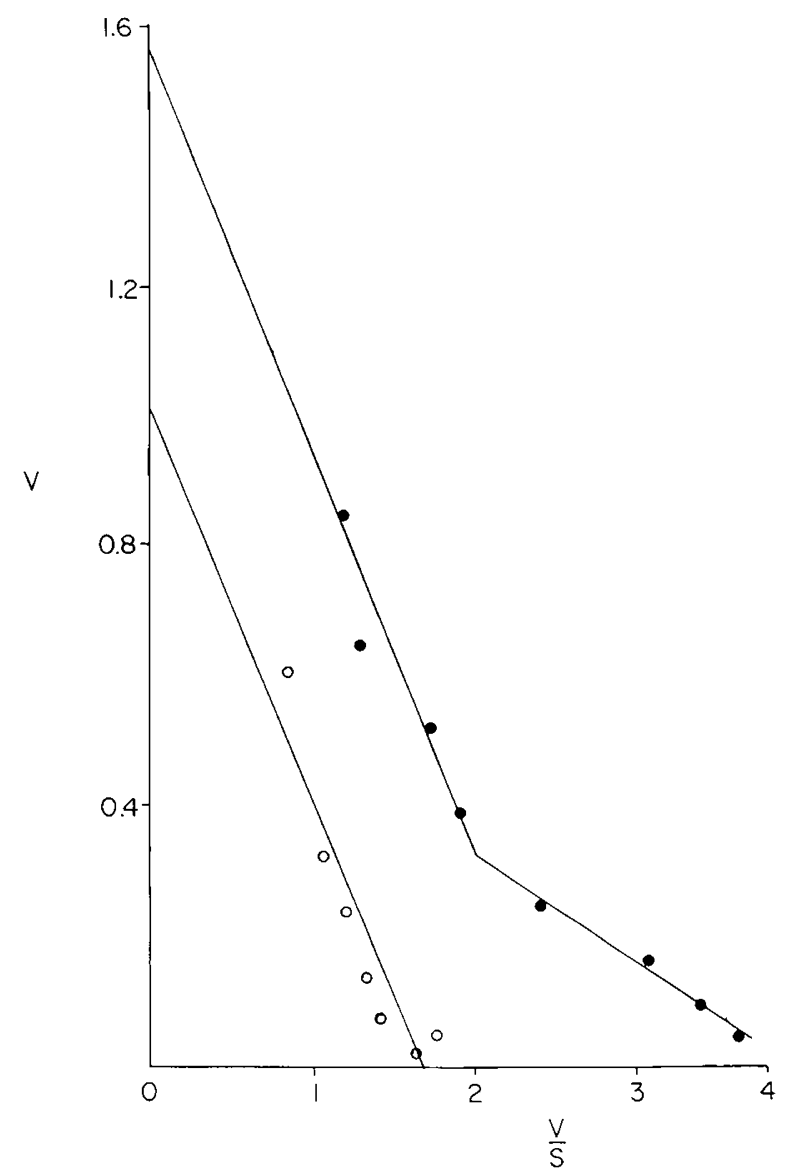

Fig. 2. A Hofstee plot of the concentration dependence of cystine uptake by isolated renal cortical tubules from adult dogs. Adult tubules were incubated for $5 \mathrm{~min}$ with $0.1 \mu \mathrm{Ci} / \mathrm{ml}\left[{ }^{35} \mathrm{~S}\right]$-L-cystine and sufficient unlabeled cystine to give the desired concentrations over the range of 0.01 to $0.7 \mathrm{mM}$. $V$ represents the velocity of uptake in $\mathrm{mmol} /$ liter intracellular fluid per $5 \mathrm{~min}$. $S$ represents the substrate concentration in $\mathrm{mM}$. Closed circles represent uptake in the absence of any competition and open circles represent the uptake in the presence of $3 \mathrm{mM}$ lysine. Each point represents the mean of at least 10 determinations.

$<0.01)$ and low affinity $(p<0.01)$ systems. The maximal transport velocities of the newborn systems were, however, much lower than those of the adult. These much lower Vmax rates gave rise to the lower uptake values by the newborn tubules, despite the higher affinity for the carriers.

Competition with lysine. Since previous in vitro studies using isolated rat renal (14) and brushborder membrane vesicles (17), have shown competition between lysine and cystine for the low $\mathrm{Km}$ system, the effect of lysine on the concentration dependence 
Table 4. Kinetic parameters of cystine uptake in the dog*

\begin{tabular}{|c|c|c|c|c|}
\hline \multirow[b]{2}{*}{$\begin{array}{c}\text { Newborn } \\
\text { Adult }\end{array}$} & \multicolumn{2}{|c|}{ High Affinity System } & \multicolumn{2}{|c|}{ Low Affinity System } \\
\hline & $\begin{array}{c}\mathrm{Km}_{1} \\
0.07 \pm 0.01 \dagger \\
0.16 \pm 0.02\end{array}$ & $\begin{array}{l}V \max _{1} \\
0.03 \pm 0.01 \ddagger \\
0.12 \pm 0.03\end{array}$ & $\begin{array}{c}\mathrm{Km}_{2} \\
0.32 \pm 0.03 \dagger \\
0.62 \pm 0.08\end{array}$ & $\begin{array}{c}V_{\max _{2}} \\
0.08 \pm 0.02 \dagger \\
0.31 \pm 0.03\end{array}$ \\
\hline
\end{tabular}

* Renal cortical tubules isolated from adult and newborn dog kidney were incubated with $0.1 \mu \mathrm{Ci} / \mathrm{ml}\left[{ }^{35} \mathrm{~S}\right]$-L-cystine plus sufficient unlabeled cystine to give the desired concentration over the range of $0.01-0.7 \mathrm{mM}$. The intracellular radioactivity was analyzed after 5 min of incubation with adult tubules and $15 \mathrm{~min}$ with newborn tubules. The kinetic parameters were determined from Hofstee plots of the data. The Km is expressed as $\mathrm{mM}$ and $\mathrm{Vmax}$ as $\mathrm{mmol} /$ liter intracellular fluid per min. The values represent the mean \pm SEM for five adult and five newborn dogs.

$\dagger p<0.01$ when comparing the newborn kinetic parameter with the corresponding adult value.

$\ddagger p<0.05$ when comparing the newborn kinetic parameter with the corresponding adult value.

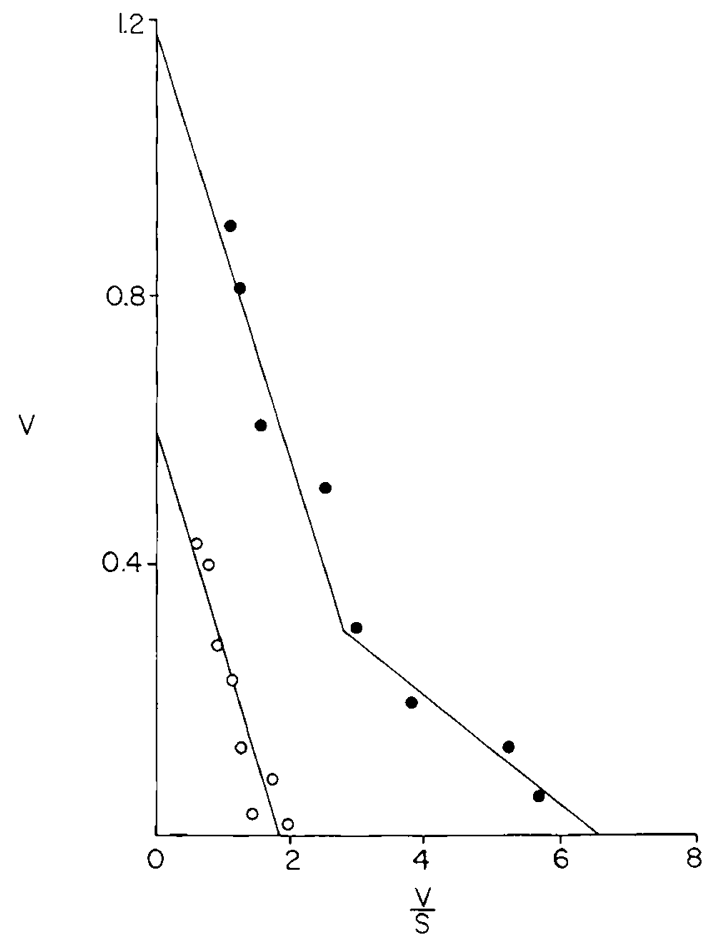

Fig. 3. A Hofstee plot of the concentration dependence of cystine uptake by isolated renal tubules from newborn dogs. Newborn tubules were incubated for $15 \mathrm{~min}$ with $0.1 \mu \mathrm{Ci} / \mathrm{ml}\left[{ }^{35} \mathrm{~S}\right]$-L-cystine and sufficient unlabeled cystine to give the desired concentrations over the range of 0.01 to $0.7 \mathrm{mM}$. $V$ represents the substrate concentration in $\mathrm{mM}$. Closed circles represent the uptake in the absence of any inhibitor and open circles represent uptake in the presence of $3 \mathrm{mM}$ lysine. Each closed point represents the mean of eight determinations and each open circle represents the mean of four determinations.

of cystine uptake was examined. Lysine significantly inhibited the uptake of cystine by the adult tubules, especially over the lower concentration range, such that only a single transport system was observed. (Fig. 2) The slope of this single line was statistically different from that of the low $\mathrm{Km}$ system $(p<0.01)$, but it was not different from the slope of the high $\mathrm{Km}$ system $(p$ $<0.9)$. This suggested that the interaction occurred on the low Km system.

With newborn tubules, lysine had a similar effect on cystine uptake (Fig. 3). The slope of single line describing the inhibited cystine uptake is significantly different from that of the low $\mathrm{Km}$ system $(p<0.05)$; but not that of the high $\mathrm{Km}$ system $(p<0.5)$.

\section{DISCUSSION}

Cystine is among the group of amino acids that exhibit a lower fractional reabsorption and increased urinary excretion in new- born animals. This has been examined in human clearance studies by Brodehl (18) and the hyperexcretion documented in the rat (13) and suggested in the dog (6). In the present work, decreased fractional reabsorption of cystine by newborn dogs has been documented, but this rises to adult values by 21 days of age.

However, the mechanisms underlying this difference in reabsorption cannot be discerned by clearance studies. To examine these mechanisms, developmental studies of cystine transport have utilized several in vitro renal cortical tissue preparations. In earlier experiments cystine uptake by rat renal cortical slices was examined $(13,16,19,20)$, but the cortical slice has been shown to provide an inadequate picture of cystine transport mechanisms $(13,14,17)$. Isolated renal tubule fragments, however, offer a more complete view of the processes involved $(13,14)$. Indeed, the findings in isolated adult rat renal tubules parallel those obtained with brushborder membrane vesicles (17). The method employed for isolating renal cortical tubules was originally described by Burg and Orloff (12) and yields a mixture of tubular segments and glomeruli; although, the predominant segment is from the proximal tubule (12). Refinements of this technique have been developed which give a more enriched preparation of proximal tubules $(21,22)$, but these newer methods have not yet been adapted to very immature animals.

In tubule preparations from newborn dogs, cystine uptake was lower than that of the adult dog, corresponding to the lower fraction reabsorption observed in vivo. From Figure 1, the decreased uptake occurred at both high and low cystine concentrations. Further, this difference in uptake was noted at early time points which more closely reflect initial rates, suggesting that the impairment in cystine reabsorption by newborn dogs could be due, in part, to influx events. The lower uptake did not appear to be related to intracellular metabolism since tubules from both age groups significantly reduced cystine to cysteine.

Concentration dependence studies indicated that preparations from both age groups had two systems for cystine uptake. Therefore, the change in renal reabsorption cannot be ascribed to the acquisition of new transport systems with maturation. The affinity of the newborn systems for cystine uptake was higher than the corresponding adult systems, but this was offset by the markedly reduced maximal transport velocities of the systems in the newborn compared to the adult systems. It would appear then that the increase in uptake with maturation is due mainly to an increase in the number or efficiency of the cystine transport sites.

Tubules from both age groups of dogs avidly reduced the transported cystine to cysteine a characteristic of cystine transport in other mammals $(13,14,16)$. This reductive step is not necessary for cystine transport since brushborder membrane vesicles, which lack the ability to reduce cystine, take it up (17). Cystine reduction may play a role in the rate at which cystine is taken up. However, the difference in the initial uptake between tubules from adult dogs and immature dogs does not appear to be related to a difference in intracellular metabolism of cystine since the transported cystine is nearly completely metabolized in both age groups. 
Lysine appeared to inhibit only the high affinity system for cystine uptake in both newborn and adult dogs. Similarly, two systems for cystine uptake were noted in rat isolated renal cortical tubules and brushborder membranes of which only the high affinity system was inhibited by lysine. A shared transport system for cystine and dibasic amino acids has been postulated for the human kidney, as well, suggesting that this may be a common characteristic of the mammalian kidney (23).

However, there are differences in cystine uptake in vitro with development between the rat and dog. In the rat, higher distribution ratios were obtained in renal tubule cells from immature animals then in adult cells, especially at later time points (13). Two systems for cystine uptake were seen in both the newborn and adult rat tubule as in the dog, but transport via the high affinity system was increased in the newborn rat (13). Thus, the "physiological" cystinuria of the neonatal rat was not related to a lower rate of cystine influx into renal tubule cells, indicating that mechanisms other than defective brushborder transport of cystine were responsible. One such mechanism may be impairment of flux out of the newborn cell, accounting for the higher distribution ratios in the newborn rat. Decreased movement across the basolateral membrane could impede transcellular transport and net reabsorption. It thus appears that there are species differences in the maturation of the cystine transport processes. Differences in the maturational events underlying glycine $(8,24)$ and sugar $(25,26)$ uptake between rat and dog tubules have previously been described. This leads to the conclusion that there are diverse explanations for the physiological aminoaciduria in the newborn. The recent development of a technique to isolate the brushborder membrane from the newborn proximal tubule (27) and the future development of methods to isolate the basolateral membrane may offer a means to answer some of the questions raised by the isolate tubule.

Acknowledgments. The authors acknowledge the excellent technical assistance provided by Mrs. Louise M. Pepe and Ms. Kristina Ginkinger.

\section{REFERENCES}

1. Segal S, Thier SO 1983 Cystinuria. In: Stanbury JB, Wynaarden JB, Fredrickson DS, Goldstein JL, Brown MS (eds) The Metabolic Basis of Inherited Disease, 5th ed. McGraw-Hill Book Co., New York, pp 1774-1791

2. Bovee KC, Segal S 1984 Renal tubule reabsorption of amino acids after lysine loading of cystinuric dogs. Metabolism 33:602-607

3. Bovee KC, Thier SO, Rea C, Segal S 1974 Renal clearance of amino acids in canine cystinuria. Metabolism 23:51-57
4. Brand E, Cahill CF 1936 Canine cystinuria. III. J Biol Chem 114:XV

5. Holtzapple P, Rea C, Bovee K, Segal S 1971 Characteristics of cystine and lysine transport in renal and jejunal tissue from cystinuric dogs. Metabolism 20:1016-1022

6. Blazer-Yost B, Jezyk PF 1979 Free amino acids in the plasma and urine of dogs from birth to senescence. Am J Vet Res 40:832-838

7. Holtzapple P, Bovee K, Rea C, Segal S 1981 Amino acid uptake by kidney and jejunal tissue from dogs with cystine stones. Science 166:1525-1527

8. Medow MS, Foreman JW, Bovee KC, Segal S 1982 Developmental changes of glycine transport in the dog. Biochim Biophys Acta 693:85-92

9. Davidson WD, Sackner MA 1963 Simplification of the anthrone method for the determination of clearance studies. J Lab Clin Med 62:351-358

10. DiGeorgio J 1974 Non-protein nitrogenous constituents (other than amino acids). In: Henry RJ, Cannon DC, Winkelman JW (eds) Clinical Chemistry: Principles and Techniques, 2nd ed. Harper and Row, Hagerstown, MD, pp $541-553$

11. Stein WH, Moore S 1954 The free amino acids of human blood plasma. J Biol Chem 211:915-959

12. Burg M, Orloff J 1962 Oxygen consumption and active transport in separated renal tubules. Am J Physiol 203:327-330

13. Hwang SM, Foreman JW, Segal S 1982 Developmental pattern of cystine transport in isolated rat renal tubules. Biochim Biophys Acta 690:145-153

14. Foreman JW, Hwang SM, Segal S 1980 Transport interactions of cystine and dibasic amino acids in isolated rat renal tubules. Metabolism 29:53-61

15. States B, Segal S 1969 Thin-layer chromatographic separation of cystine and the N-ethylmaleimide adducts of cysteine and glutathione. Anal Biochem 27:323-329

16. Segal S, Crawhall JC 1968 Characteristics of cystine and cysteine transport in rat kidney cortex slices. Proc Natl Acad Sci USA 59:231-237

17. McNamara PD, Pepe LM, Segal S 1981 Cystine uptake by rat renal brushborder vesicles. Biochem J 194:443-449

18. Brodehl J 1976 Postnatal development of tubular amino acid reabsorption. In: Silbernagl S, Lang F, Greger R (eds) Amino Acid Transport and Uric Acid Transport. Georg Thieme Publishers, Stuttgart, pp 128-135

19. Segal S, Smith I 1969 Delineation of separate transport systems in rat kidney cortex for L-lysine and L-cystine by developmental patterns. Biochem Biophys Res Commun 35:771-777.

20. Segal S, Smith I 1969 Delineation of cystine and cysteine transport systems in rat kidney cortex by developmental patterns. Proc Natl Acad Sci USA 63:926-933

21. Vinay P, Gougoux A, Lemieux G 1981 Isolation of a pure suspension of rat proximal tubules. Am J Physiol 241:F403-F411

22. Balaban RS, Soltoff SP, Storey JM, Mandel LJ 1980 Improved renal cortical tubules suspension: spectrophotometric study of $\mathrm{O}_{2}$ delivery. Am J Physiol 238:F50-F59

23. Dent CE, Rose GA 1951 Amino acid metabolism in cystinuria. Q J Med 20:205-219

24. Reynolds R, Roth KS, Hwang SM, Segal S 1978 On the development of glycine transport systems by rat renal cortex. Biochim Biophys Acta 571:274-284

25. Roth KS, Hwang SM, Yudkoff M, Segal S 1978 The ontogeny of sugar transport in the kidney. Pediatr Res 12:1127-1131

26. Foreman JW, Medow MS, Wald H, Ginkinger K, Segal S 1984 Developmental aspects of sugar transport by isolated dog renal cortical tubules. Pediatr Res 18:719-723

27. Medow MS, Roth KS, Ginkinger K, Segal S 1983 Renal brushborder membrane vesicles prepared from newborn rats by free-flow electrophoresis and their proline uptake. Biochem J 214:209-214 